\title{
BILATERAL VISUAL LOSS AFTER LIPOSUCTION: CASE REPORT AND REVIEW OF THE LITERATURE
}

\author{
Frederico Castelo Moura, Leonardo Provetti Cunha, Mário Luiz Ribeiro Monteiro
}

\section{INTRODUCTION}

Severe visual loss after a general surgical procedure can be a devastating complication for both surgeon and patient. Although visual loss can be the result of damage to any structure in the eye, most cases of such a complication are the result of ischemic damage to both the anterior and posterior portions of the optic nerve..$^{1-6}$ Ischemic optic neuropathy (ION) is therefore a potentially devastating and untreatable, albeit rare complication of general surgery, usually occurring in the immediate postoperative period. Precipitating factors for such occurrences include prolonged hypotension, anemia, significant intraoperative hydration, surgical trauma, gastrointestinal bleeding, hemorrhage, shock, and long operative times, ${ }^{2,3}$ usually occurring after cardiopulmonary, orthopedic, and neurosurgical procedures. ${ }^{1-6}$ Recently, 3 cases of ION after liposuction, a simple and commonly performed operation, have been reported. ${ }^{7-9}$ The purpose of this paper is to report 1 further case of this unusual event and to review the possible mechanisms and preventive measures for such an occurrence.

\section{CASE REPORT}

A 49-year-old woman underwent tumescent liposuction of the thighs, dorsum, and hips associated with removal of breast nodules. During the surgery, which was performed under spinal-epidural anesthesia and sedation, approximately $3,000 \mathrm{~mL}$ of fat was removed. The procedure was complicated by a large amount of blood loss and she remained in the hospital 2 days after surgery at which time she developed headache and a temperature of $38.6^{\circ} \mathrm{C}$. Oral ceftriaxone was prescribed, although no infection site was identified. Four days after surgery, she noticed blurred vision in the right eye and a dark spot in the inferior field of vision in the left eye. She denied having any previous ocular symptom, or ocular pain. Preoperatively, she was in good general health with no systemic disease. An ophthalmic examination documented

Division of Ophthalmology, São Paulo University Medical School - São Paulo/SP, Brazil.

Email: mlrmonteiro@terra.com.br an inferior altitudinal field defect and optic disc edema in both eyes with a peripapillary hemorrhage in the OS. Neurological examination was normal, and a lumbar puncture revealed an opening pressure of $19 \mathrm{~cm} \mathrm{H}_{2} \mathrm{O}$. No abnormalities were noted in the cerebrospinal fluid. Magnetic resonance imaging of the brain was normal, and pulse therapy with 1 gram of methylprednisolone/day during 3 days, followed by oral prednisone, was administered with only mild improvement in vision.

Laboratory investigation 2 weeks after surgery revealed a blood cell count of 3.76 million/mm, hemoglobin of 11.7 $\mathrm{g} / \mathrm{dL}$, hematocrit of $34.5 \%$, and a sedimentation rate of 12 $\mathrm{mm}$. Protein S, Protein C, and antiphospholipid antibody were negative. Forty days after surgery she was referred for neuro-ophthalmic consultation. The best-corrected visual acuity was $20 / 30$ in each eye. The pupils were equal in size, slightly sluggish to light, but a relative afferent defect was not found. Extra ocular motility, slit lamp examination, and intraocular pressure measurements were unrevealing. Fundus examination revealed small and crowded discs with pallor superiorly in both eyes (Figure 1). Goldmann visual field disclosed bilateral dense inferior altitudinal defect (Figure 2). Oral corticosteroid was tapered and discontinued. One month later visual acuity was 20/25 in each eye, but the visual fields were unchanged. A repeat blood analysis revealed a blood cell count of $4.55 \mathrm{million} / \mathrm{mm}$, hemoglobin of $13.6 \mathrm{~g} / \mathrm{dL}$, and hematocrit of $42.0 \%$.
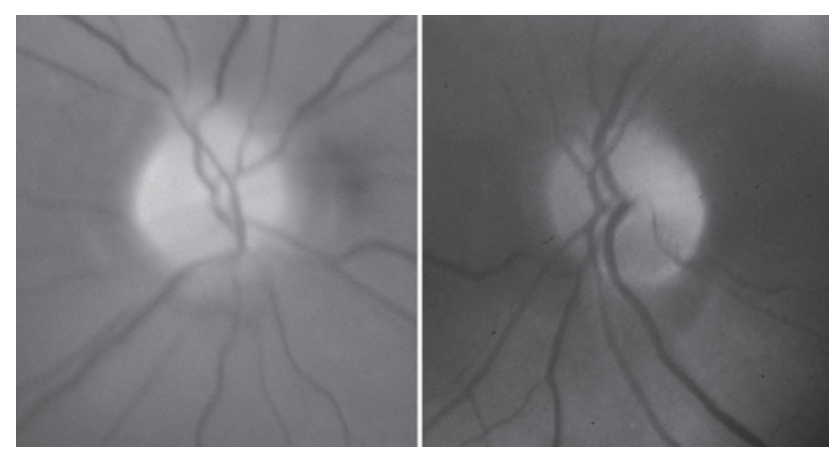

Figure 1 - Fundus photograph 40 days after visual loss showing small ("crowded") optic discs with pallor most prominent superiorly in both eyes. 


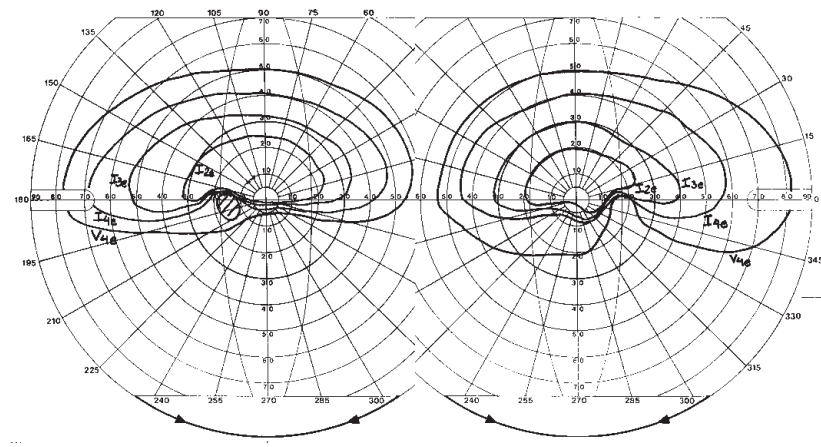

Figure 2 - Goldmann visual field showing severe inferior visual field defect in both eyes.

\section{DISCUSSION}

The term ischemic optic neuropathy (ION) is used as a general and inclusive term to refer to all presumed ischemic causes of optic neuropathy. It can be subdivided into anterior ischemic optic neuropathy (AION) characterized by visible optic disc changes (swelling of the disc and peripapillary hemorrhages) and posterior (or retrobulbar) ischemic optic neuropathy (PION), in which no abnormality of the optic disc is evident (at least initially).

Anterior ischemic optic neuropathy is much more common than posterior ischemic optic neuropathy, accounting for about $90 \%$ of cases of ION. It can be classified as arteritic (A-AION), caused by several vasculitis, especially giant cell arteritis, and non-arteritic (NA-AION), not related to such conditions. Nonarteritic anterior ischemic optic neuropathy is the result of the interruption of oxygen supply to the optic nerve head anterior to the lamina cribrosa, and the major contributing factors include failure of perfusion pressure resulting from a severe drop in blood (such as in systemic hemorrhage and surgical hypotension), critical decline of oxygen-transport by the blood (such as in severe anemia due to blood loss), and increased resistance to blood flow (such as in atherosclerosis, polycythemia, and small optic disc). ${ }^{10}$ Patients with NA-AION frequently have a small optic disc called "small cup-disc ratio" or "crowded disc," which implies a small optic disc diameter and a smaller scleral canal. ${ }^{10}$ Burde $^{11}$ coined the term "disc at risk" to describe such discs, and this morphologic finding is an important risk factor for NA-AION.

Posterior ischemic optic neuropathy, on the other hand, usually occurs in the setting of severe anemia and hypotension caused by hemorrhage from surgery and gastrointestinal bleeding, even in healthy subjects with no systemic vascular risk factors. ${ }^{12} \mathrm{~A}$ review of the literature indicates that the most frequent precipitating cause is cardiopulmonary bypass. In most cases of ION associated with cardiopulmonary bypasses, hypotension, anemia, or both were implicated as contributing etiologic factors. However, in many cases, the intraoperative levels of blood pressure and anemia were frequently considered acceptable in anesthesia practice.

Our patient had a postoperative ION after liposuction precipitated by acute blood loss and hypotension. Liposuction surgery is a procedure that can help sculpt the body by removing unwanted fat from specific areas, including the $a b-$ domen, hips, buttocks, and thighs. It is currently the most commonly performed aesthetic procedure worldwide. ${ }^{10,13}$ The safety of liposuction has improved since the introduction of the tumescent technique, designed to remove approximately $1500 \mathrm{~mL}$ of localized fat for cosmetics in nonobese subjects. Utiyama et $\mathrm{al}^{14}$ recently reviewed retrospectively 288 surgeries performed in 266 patients during a 6-year period using the tumescent technique. The liposuctioned locations were the abdomen, trochanteric region, flank, submentonian region, inner thigh region, axillae, inner knee region, back, and arm. Most patients had localized surgeries with a small volume of aspirate fluid. The authors did not find complications in the intraoperative and postoperative period and concluded that liposuction is a safe procedure.

However, while the safety of the procedure has improved, the volume of liposuction has increased, and unfortunately the procedure has frequently been used in obese patients. Large-volume liposuction (> $1500 \mathrm{~mL}$ of aspirate) may be associated with a relatively high rate of morbidity and mortality because of hemodynamic complications. Patients are exposed to prolonged procedures, fluid shifts, and infusion of high doses of epinephrine and lidocaine that are added to the wetting solution on account of their analgesic and hemostatic effects. Hemodilution in the postoperative period is probably the result of fluid shift from the operative field and blood loss during surgery, because $25 \%$ to $30 \%$ of the aspirate can be blood. . $^{10,13,15,16}$

Although liposuction is considered a safe procedure, especially after the introduction of the tumescent technique, ${ }^{17,18}$ serious local and systemic complications have been reported, such as pulmonary fat embolism, infection, pituitary apoplexy, deep venous thrombosis, and death ${ }^{13,15,16,19,20}$. Visual loss after liposuction is a rare complication, with only 3 prior reports. ${ }^{7-9}$ Minagar et al $^{7}$ described a 47 -year-old woman with no atherosclerotic risk factors who underwent liposuction and developed postoperative hypotension and anemia. Visual loss developed in the right eye during the second postoperative day, and on ophthalmoscopy, pallid optic disc edema was noted. The left optic disc was not crowded and had a normal appearance. The brain MRI and MRA were normal. The authors concluded that the patient had a postoperative AION precipitated by acute blood loss and hypotension. Sigbatullah et $\mathrm{al}^{9}$ recently studied a similar patient with unilateral anterior ischemic optic neuropathy, with an inferior altitudinal field defect, developing 2 days after liposuction, at a time when her hematocrit was only $23.5 \%$. A possible PION in 
the right eye was considered by the authors because of the visual field depression and normal ophthalmoscopy. Foroozan and Varon ${ }^{8}$ reported on a patient who developed bilateral AION after high-volume liposuction. The patient also developed pulmonary embolism and dural venous sinus thrombosis. On examination, bilateral pallid optic disc edema and hemorrhages were present. Transverse sinus thrombosis was shown on MRV, but the intracranial pressure measurements were not reported. Severe anemia with hemoglobin of $7.0 \mathrm{~g} / \mathrm{dL}$, and a hematocrit of $21.6 \%$ was documented in the postoperative period.

In the above-mentioned cases, visual loss was most likely precipitated by postoperative severe anemia resulting in acute AION. Rapid diagnosis of visual loss due to postoperative ION and aggressive management of anemia and hypotension do not seem to significantly improve the prognosis of these patients, ${ }^{10}$ but should be tried in individual cases. Visual loss associated with blood loss and hypotension may be unilateral but is often bilateral, ranging from irreversible total blindness to mild transient deficits. Although the onset is usually prompt at the time of hemorrhage, it is delayed by more than 3 days in a third of cases, and beyond 10 days in some instances. Approximately $50 \%$ of patients experience some recovery of sight. ${ }^{21}$

Our patient suffered an acute blood loss after liposuction that was complicated by hemorrhage in the postoperative period. Presumably, hypotension and blood loss from the surgery associated with the postoperative hemorrhagic complication were causative factors for her bilateral AION. Furthermore, she had small and "crowded discs," another important risk factor for NA-AION, ${ }^{11}$ which may have acted as a predisposing factor. This case is important because it emphasizes the fact that ION is a rare but potentially devastating complication of liposuction. Since liposuction is a frequently performed surgery, physicians should be aware of such a possibility. Anemia, hypotension, long duration of surgery and significant intraoperative hydration may all be risk factors for this condition. All patients undergoing liposuction should be informed about the low but definite risk of this condition, and every attempt should be made during surgery to maintain stable hemoglobin and mean arterial pressure and to avoid overhydration.

\section{REFERENCES}

1. Purvin V, Kuzma B. Intraorbital optic nerve signal hyperintensity on magnetic resonance imaging sequences in perioperative hypotensive ischemic optic neuropathy. J Neuroophthalmol. 2005;25:202-4.

2. Rupp-Montpetit K, Moody ML. Visual loss as a complication of nonophthalmic surgery: a review of the literature. Insight. 2005;30:10-7.

3. Buono LM, Foroozan R. Perioperative posterior ischemic optic neuropathy: review of the literature. Surv Ophthalmol. 2005;50:15-26.

4. Gilbert TB. Acute visual loss following cardiopulmonary bypass: model case presentation and discussion. J Neurosurg Anesthesiol. 2004;16:756.

5. Luna JD, Artal N, Reviglio VE, and Juarez CP. LASIK-induced optic neuropathy. Ophthalmology. 2002;109:817-8

6. Harris MJ. Incidence of NAION with cataract extraction Ophthalmology. 2002;109:630; author reply 630.

7. Minagar A, Schatz NJ, and Glaser JS. Liposuction and ischemic optic neuropathy. Case report and review of literature. J Neurol Sci. 2000;181:132-6.

8. Foroozan R, Varon J. Bilateral anterior ischemic optic neuropathy after liposuction. J Neuroophthalmol. 2004;24:211-3.

9. Sibgatullah MKM, Zerykier A, Volpe S. Ischemic optic neuropathy after liposuction: case report and review. J Neuroophthalmol. 2005;29:91-3.

10. Kenkel JM, Lipschitz AH, Luby M, Kallmeyer I, Sorokin E, Appelt E, et al. Hemodynamic physiology and thermoregulation in liposuction. Plast Reconstr Surg. 2004;114:503-13; discussion 514-5.

11. Burde RM. Optic disk risk factors for nonarteritic anterior ischemic optic neuropathy. Am J Ophthalmol. 1993;116:759-64.
12. Murphy MA. Bilateral posterior ischemic optic neuropathy after lumbar spine surgery. Ophthalmology. 2003;110:1454-7.

13. Albin R, de Campo T. Large-volume liposuction in 181 patients. Aesthetic Plast Surg. 1999;23:5-15.

14. Utiyama Y, Chiacchio ND, Yokomizo V, Benemond T, Metelmann U. Estudo retrospectivo de 288 lipoaspirações realizadas no Serviço de Dermatologia do Hospital do Sevidor Público Municipal de São Paulo. An Bras Dermatol. 2003;78:435-42.

15. Courtiss EH, Choucair RJ, Donelan MB. Large-volume suction lipectomy: an analysis of 108 patients. Plast Reconstr Surg. 1992;89:1068-79; discussion 1080-2.

16. Cohen A, Kishore K, Wolansky L, and Frohman L. Pituitary apoplexy occurring during large volume liposuction surgery. J Neuroophthalmol, $2004 ; 24: 31-3$

17. Klein JA, Tumescent technique for local anesthesia improves safety in large-volume liposuction. Plast Reconstr Surg. 1993;92:1085-98; discussion 1099-100

18. Klein JA, The tumescent technique. Anesthesia and modified liposuction technique. Dermatol Clin. 1990;8:425-37.

19. Rao RB, Ely SF, Hoffman RS. Deaths related to liposuction. N Engl J Med. 1999;340:1471-5.

20. Grazer FM, de Jong RH. Fatal outcomes from liposuction: census survey of cosmetic surgeons. Plast Reconstr Surg. 2000;105:436-46; discussion 447-8.

21. Johnson MW, Kincaid MC, and Trobe JD. Bilateral retrobulbar optic nerve infarctions after blood loss and hypotension. A clinicopathologic case study. Ophthalmology. 1987;94:1577-84. 